\title{
A Gramática de Grafos como uma alternativa para o desenvolvimento do Pensamento Computacional na Educação Básica*
}

\author{
Braz A. S. Junior ${ }^{1}$, Simone A. C. Cavalheiro ${ }^{1}$, Luciana Foss ${ }^{1}$ \\ ${ }^{1}$ Laboratório de Fundamentos da Computação - Universidade Federal de Pelotas (UFPel) \\ Caixa Postal 354 - 96.010-610 - Pelotas - RS - Brasil \\ \{badsjunior, simone.costa, lfoss\}@inf.ufpel.br
}

\begin{abstract}
This paper proposes the creation of a game based on Graph Grammars. The goal of this work is offering a playful option to develop Computational Thinking without using a computer. Particularly, this approach includes the concepts of algorithms, simulation, abstraction, parallelism and analysis.

Resumo. Este artigo propõe a criação de um jogo fundamentado em Gramática de Grafos. O objetivo desta proposta é oferecer uma opção lúdica para o desenvolvimento de habilidades do Pensamento Computacional sem o uso do computador. Particularmente, esta abordagem engloba os conceitos de algoritmos, simulação, abstração, paralelismo e análise.
\end{abstract}

\section{Introdução}

Em 2006, Jeannette Wing [Wing 2006] expôs que as habilidades que os profissionais da ciência da computação desenvolvem não são úteis somente para sua área, mas são habilidades de propósito geral, fundamentais para todos em um mundo moderno. O conjunto destas habilidades representa o conceito de Pensamento Computacional (PC). Este conceito foi consolidado por profissionais da área da educação, a International Society for Tecnology in Education (ISTE) e a Computer Science Teachers Association (CSTA), através da criação de uma definição operacional para o termo Pensamento Computacional [CSTA and ISTE 2011], que exploramos na seção 2.

Uma das formas de se desenvolver o PC que tem ganhado popularidade recentemente é através do ensino de programação. Em 2013, houve uma campanha global de desmitificação da programação, a Hour of Code, com um vídeo ${ }^{1}$ viral incentivando as pessoas a aprenderem a programar, que contou com personalidades do mundo da tecnologia como Mark Zuckerberg, do Facebook, e Bill Gates, da Microsoft. As escolhas comuns de abordagens para a introdução à solução de problemas na educação básica e, consequente desenvolvimento do PC, são: programação em blocos, linguagens imperativas, funcionais, entre outras.

Este trabalho visa explorar a Gramática de Grafos (GG) como uma abordagem alternativa para se desenvolver o PC na Educação Básica. A inovação desta proposta está na adoção de uma linguagem que permite uma forma rigorosa e eficaz de modelagem, assim, viabilizando a introdução da verificação formal já no primeiro contato com

\footnotetext{
*Este trabalho é parcialmente financiado pelo CNPq - Processo 447463/2014-4.

${ }^{1}$ What Most Schools Don't Teach - https://www.youtube.com/watch?v=nKIu9yen5nc
} 
a especificação de soluções de problemas. Além disso, GG possui descrição visual, e consegue expressar de forma natural construções complexas, como as de distribuição, concorrência e paralelismo [Ehrig et al. 1997], que são pouco exploradas nas abordagens comumente utilizadas no ensino de programação na Educação Básica.

A proposta deste trabalho é a especificação e criação de um jogo educacional fundamentado em GG. O escopo de aplicação é a educação básica e, para se tornar atrativo aos estudantes, prioriza-se a existência de componentes lúdicos. Além disso, a abordagem se caracteriza como uma atividade desplugada, já que não necessita de computador. Como relatado em [Bell et al. 2015], a ciência da computação é frequentemente ensinada priorizando programação, mas nem todo aluno acha isto muito motivante, na verdade, o computador muitas vezes se torna uma distração. Além disso, é preciso considerar que muitos ambientes de aprendizado não possuem a infraestrutura e o suporte necessário para oferecer aulas regulares com a utilização de computadores e rede conectada à internet.

Na seção 2, são apresentados a definição operacional e os conceitos básicos do PC. Na seção 3, é descrita uma breve introdução à GG. Na seção 4, são levantados alguns dos conceitos e habilidades do PC que podem ser exploradas com GG. A seção 5 trata da descrição do jogo e a seção 6 traz algumas considerações finais.

\section{Pensamento Computacional}

Segundo sua definição operacional [CSTA and ISTE 2011], PC é um processo de resolução de problemas que inclui (mas não é limitado a) as seguintes características: formular problemas de uma maneira que nos permita usar um computador ou outras ferramentas para ajudar a resolvê-los; organizar e analisar dados logicamente; representar dados através de abstrações, como modelos e simulações; automatizar soluções através do pensamento algorítmico (uma série de passos ordenados); identificar, analisar e implementar possíveis soluções com o objetivo de alcançar a mais eficiente e efetiva combinação de passos e recursos; e generalizar e transferir este processo de solução de problemas para uma ampla variedade de problemas.

Essas habilidades são sustentadas e aprimoradas por um número de disposições ou atitudes que são dimensões essenciais do PC. Essas disposições ou atitudes incluem: confiança em lidar com complexidade; persistência em trabalhar com problemas difíceis; tolerância à ambiguidade; a habilidade de lidar com problemas em aberto; e a habilidade de se comunicar e trabalhar em grupo para alcançar uma solução ou objetivo comum.

A abstração e a análise constituem pilares do PC. A abstração é a capacidade de extrair apenas as características importantes de um problema para chegar à sua solução. Problemas com elevado grau de complexidade tornam-se difíceis de serem resolvidos, caso não haja uma abstração adequada. A análise é o estudo dos resultados gerados pela especificação. Se eles não saírem como o esperado, há a possibilidade de não ter sido escolhido o nível de abstração adequado ou até mesmo de não ter sido planejada a solução corretamente.

No toolkit [CSTA and ISTE 2011] elaborado pela ISTE e CSTA, destaca-se um quadro de progressão com nove conceitos da computação fundamentais para o desenvolvimento do PC: coleta de dados, análise de dados, representação de dados, decomposição de problemas, algoritmos e procedimentos, automação, simulação e paralelismo. 


\section{Gramática de Grafos}

Em termos gerais, as GG [Ehrig et al. 1997] são uma generalização de gramáticas de Chomsky, substituindo strings por grafos. Uma GG é composta por três elementos:

Grafo tipo: o grafo tipo estabelece os tipos de vértices e arcos permitidos no sistema. Ou seja, um sistema especificado em GG é restrito ao uso dos tipos de vértices e arcos contidos em seu grafo tipo.

Grafo inicial: o grafo inicial descreve a configuração inicial do sistema.

Regras: regras são morfismos entre grafos que definem as possíveis mudanças do sistema, sendo compostas por: um grafo esquerdo (L); um grafo direito (R); e um homomorfismo de grafos de L em R. O lado esquerdo determina os componentes que devem estar presentes no grafo que descreve a configuração corrente do sistema (grafo estado) para que a regra seja aplicada. Enquanto o lado direito especifica as modificações que devem ocorrer após a aplicação da regra.

A semântica de uma GG é descrita por aplicações de regras a partir do grafo inicial. As regras são aplicadas a um grafo estado quando existe um match (um morfismo total entre grafos), o qual identifica que todos os elementos do lado esquerdo da regra estão presentes no grafo estado. A especificação em GG permite a simulação e a verificação formal do sistema descrito, o que possibilita investigar a validade de propriedades.

\section{Gramática de Grafos e o Pensamento Computacional}

A adoção e promoção de GG como fundamento para a criação de um jogo educacional se justifica por sua relação com conceitos fundamentais do PC, destacados a seguir:

Abstração: a representação e especificação da solução de um problema em GG se dá em um nível de abstração mais alto do que as linguagens de programação usuais.

Análise: o uso de uma linguagem formal na especificação, permite a verificação precisa e análise de propriedades. Bem como a visualização e organização dos dados é facilitada e direta através do uso de uma linguagem visual.

Simulação: na especificação de uma GG, a aplicação de regras a partir do estado inicial simula os comportamentos possíveis do sistema descrito.

Paralelismo: GG permite explorar conceitos usualmente complexos como concorrência e distribuição de forma natural. Devido ao seu estilo declarativo (através do uso de regras), várias regras podem ser executadas ao mesmo tempo, desde que não deletem/modifiquem os mesmos elementos do grafo que representa o estado.

\section{O Jogo}

O jogo proposto possui um tabuleiro, cartas e personagens infantis, compondo uma GG a ser manipulada pelos jogadores. Logo, ao jogar, os alunos deverão obedecer às definições formais de especificação, manipulação e transformação de grafos em uma GG, tendo assim um primeiro contato com estes conceitos, mas de forma lúdica.

Para englobar diferentes níveis de conhecimento acerca da GG, o jogo pode ser executado nos seguintes modos: o modo simples, em que os jogadores recebem um objetivo e regras prontas, devendo aplicar as regras de uma GG para chegar ao seu objetivo; o modo intermediário, em que eles recebem um objetivo, então devem definir e aplicar as regras para alcançá-lo; e o modo avançado em que eles validam propriedades do sistema ao aplicar regras. As diferentes formas de jogá-lo permitem também com que ele 
seja utilizado individualmente ou em grupo, podendo ser adaptado para atender a variadas situações, bastando ao educador julgar qual é mais conveniente.

Para ilustrar o funcionamento do jogo, a Figura 1, apresenta uma configuração do jogo no modo simples. Os vértices da GG são representados por árvores, pelo macaco (personagem do jogador) e pelo cacho de bananas (objetivo do jogo), enquanto as arestas são representadas por cipós. Neste exemplo, o jogador recebe: o objetivo (chegar à árvore que possui o cacho de bananas); uma única regra, a regra de movimentação do macaco (à direita na Figura 1); e o grafo inicial (à esquerda na Figura 1).
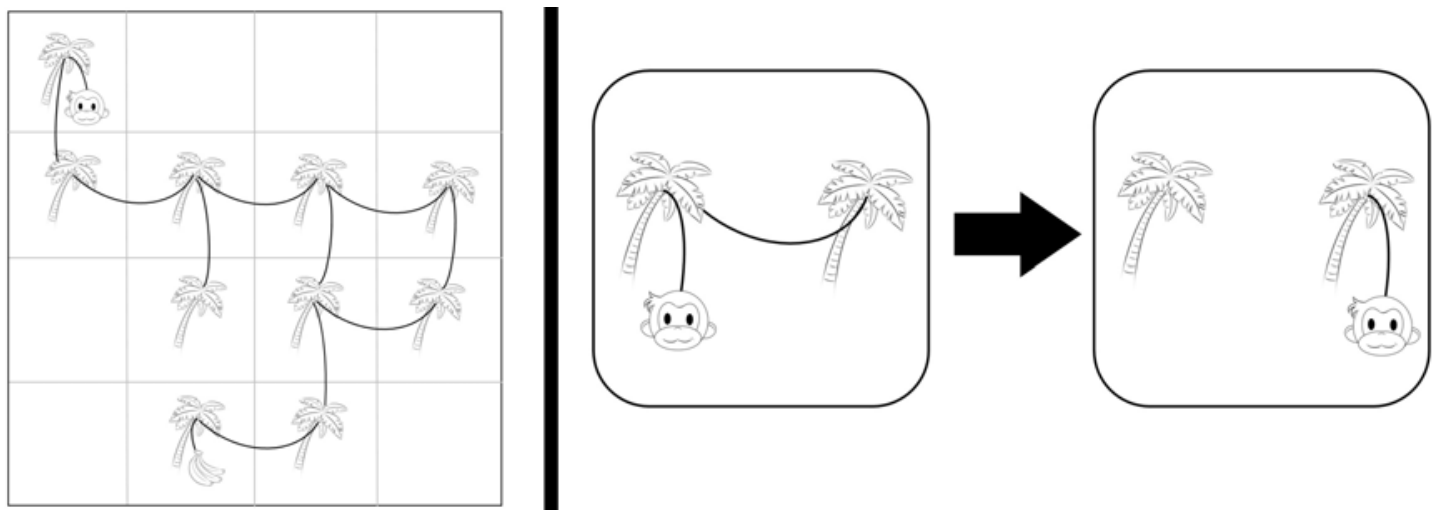

Figura 1. Grafo Inicial (à esquerda) e Regra (à direita)

Partindo do grafo inicial recebido, o jogador deve aplicar, iterativamente, a regra de movimentação do macaco até que o objetivo seja alcançado, ou não haja mais possibilidade de aplicações da regra. O jogador deverá observar que para mover o macaco de uma árvore à outra, é necessário existir um cipó entre elas e este cipó deve ser retirado do jogo após a movimentação do macaco (como descrito pela regra). Portanto, o jogador deve estar atento às aplicações que podem excluir cipós essenciais para o caminho até seu objetivo (isolando-o em uma árvore sem bananas) e evitá-las.

\section{Conclusão}

Neste artigo é proposta uma abordagem fundamentada em GG como uma alternativa para o desenvolvimento do PC na educação básica. Para isto, é apresentada a proposta de um jogo educacional capaz de simular uma GG. O produto é um jogo versátil, que pode ser jogado de diferentes maneiras, para explorar conceitos do PC de acordo com a faixa etária dos estudantes. E ainda, utiliza-se o conceito de atividade desplugada, para reduzir eventuais dificuldades em sua implementação, como a dependência da infraestrutura.

\section{Referências}

Bell, T., Witten, H., and Fellows, M. (2015). CS Unplugged.

CSTA and ISTE (2011). Computational Thinking Leadership Toolkit.

Ehrig, H. et al. (1997). Handbook of Graph Grammars and Computing by Graph Transformation, Volume 1.

Wing, J. (2006). Computational thinking. In Communications of the ACM, volume 49, pages 33-35. ACM. 